\title{
Urinary Tract Infection among Patients Visiting Ganesh Man Singh Memorial Hospital and Research Center, Lalitpur, Nepal
}

\author{
Janak Raj Dhungana ${ }^{1 *}$, Aruna Budhathoki ${ }^{1}$, Goma Poudel ${ }^{1}$, Jyotika Basnet ${ }^{1}$, Ravi Shah ${ }^{2}$ \\ ${ }^{1}$ Department of Microbiology, Tri Chandra Multiple College, Ghantaghar, Kathmandu, Nepal \\ ${ }^{2}$ Ganeshman Singh Memorial Hospital and Research Center, Lalitpur, Nepal
}

\begin{abstract}
*Corresponding author: Janak Raj Dhungana, Department of Microbiology, TriChandra Multiple College, Ghantaghar, Tribhuvan University, Kathmandu, Nepal; Email: janak_ dhungana@yahoo.com
\end{abstract}

\section{ABSTRACT}

Objectives: The objective of this study was to determine the prevalence of urinary tract infection (UTI) and antibiotic sensitivity pattern among the suspected UTI cases visiting at Ganeshman Singh Memorial Hospital Lalitpur, Nepal.

Methods: A total of 300 mid-stream urine, catheter and suprapubic aspirate from UTI suspected patients were included and processed for routine microscopy and culture and then identified by standard microbiological methods. Antibiotic susceptibility test was performed by Kirby- Bauer disc diffusion method.

Results: Out of 300 samples, $55(84.6 \%)$ mid-stream urine and $10(15.4 \%)$ catheter sample had significant bacterial growth. E. coli $(32,49.2 \%)$ was the most common isolate followed by Staphylococcus aureus (10,15.3\%), Enterobacter spp. (8,12.3\%), Klebsiella spp. (7,10.7\%), Pseudomonas aeruginosa (3,4.6\%), Proteus spp. (3,4.6\%), Acinetobacter spp. (1,1.5\%) and Enterococcus spp. (1,1.5\%). Most of the Gramnegative bacterial isolates were sensitive to Ceftriaxone (88.8\%) followed by Gentamicin (72.2\%), and Nitrofurantoin (64.8\%) and resistant to Amoxicilin (68.5\%) followed by Nalidixic Acid (53.7\%). Gram positive isolates were sensitive to Amikacin $(72.7 \%)$ followed by Imipenem $(63.6 \%)$ and Gentamicin (63.6\%) whereas resistant to Amoxycilin (72.7\%) and Ciprofloxacin (63.63\%).

Conclusion: The main cause of the UTIs was found as Gram negative bacteria. Prescription of antibiotics based on susceptibility tests would help in reduction of antibiotic resistance.

Key words: Antimicrobial susceptibility, Escherichia coli, Staphylococcus aureus, Urinary tract infection

\section{INTRODUCTION}

Urinary tract infection (UTI) is an infection caused by the presence and growth of microorganisms anywhere in the urinary tract. Urinary Tract Infection (UTI) remains the commonest bacterial infection in human population with a high rate of morbidity and financial cost as this disease encounter with both community and hospitalized patients of all age group. In contrast to men, women are more susceptible to UTI, and this is mainly due to short urethra, absence of prostatic secretion, pregnancy and easy contamination of urinary tract with faecal flora (Haider et al. 2010).

UTI is usually classified by the infection site:

Date of Submission: June 13, 2019

Published Online: December, 2019 -bladder(cystitis), kidney(pyelonephritis), and urethra(urethritis). UTIs that occur in a normal genitourinary tract with no prior instrumentation are considered as "uncomplicated," whereas "complicated" infection is diagnosed in genitourinary tracts that have structural or functional abnormalities, including instrumentation such as indwelling urethral catheters (Haider et al. 2010; Taher et al. 2009).

The common pathogens that cause UTI are E. coli, Klebsiella spp, Staphylococcus spp and other pathogens. Other pathogens include Pseudomonas, Streptococcus and MRSA. More than $95 \%$ of UTI cases are caused by bacterial pathogens, among which E. coli, the

Date of Acceptance: November 29, 2019

DOI: https:/ / doi.org/10.3126/tujm.v6i0.26593 
most leading causative organism, is responsible for the urinary tract infection. More than $80 \%$ of urinary tract infections get caused by Klebsiella spp. (Ramesh et al. 2008). Other Gram-negative bacteria that cause infection include Enterobacter spp., Pseudomonas aeruginosa, Proteus spp., Citrobacter spp., Morganella morganii, and so on. The total account of Gram-positive bacteria to cause urinary tract infection is 5 to $15 \%$ of the total bacteria, which include Enterococcus spp., Staphylococci, and Streptococci (Akram et al. 2007).

Majorities of UTIs are not life threatening and do not cause any serious disease to the human health. Nevertheless, when the bacterial pathogens that affect kidneys are involved, there is a risk of serious disease like tissue damage with an increased risk of bacteremia (Manikandan et al. 2011). Presence of bacteria, fungi and viruses, among others, could be involved most often to cause UTI. These bacteria enter the urethra and then travel to the bladder and kidneys (Benjamin 2009).

UTI is a common disease aliment among Nepalese population as well as one of the commonest nosocomial infection (Kattel et al. 2008). Nowadays, antimicrobial resistance is a global problem that threatens individual and social well-being. The changing patterns in the etiological agents of urinary tract pathogen and their sensitivities to commonly prescribed antibiotics are reported (Manikandan et al. 2011). The problems of antimicrobial resistance may be due to the fact that antibiotics can be obtained and used without medical authorization or supervision in developing countries (Pokhrel et al. 2006) such as Nepal.

This study was conducted to assess the bacteria causing UTI among the suspected patients visiting Ganeshman Singh Memorial Hospital and Research Center, Lalitpur, Nepal.

\section{MATERIALS AND METHODS}

This study was carried out among the patients visiting at Ganeshman Singh Memorial Hospital and Research Center, Lalitpur, Nepal. Three hundred samples, i.e. clinically suspected UTI defined by physician, were investigated from December 2016 to March 2017. The patients with age group ten years and more were included and mid-stream urine, catheter urine and suprapubic aspirate were collected for this study. Under macroscopic examination of urine, the specimens were observed for its colour and appearance and reported accordingly (Cheesbrough 2000).
During microscopic examination of urine, $10 \mathrm{ml}$ of urine sample was taken in a clean test tube and the sample was centrifuged at $3000 \mathrm{rpm}$ for 5 minutes. Then the supernatant was discarded and sediment was used for the wet mount preparation to detect RBC, pus cell and epithelial cell. Culture of each urine sample was done into the MacConkey agar and blood agar medium by semi-quantitative method using standard sterile inoculating loop of standard dimension $(0.001 \mathrm{ml})$. The plates were then incubated at $37^{\circ} \mathrm{C}$ for overnight. Samples showing $\geq 10^{5}$ colony forming unit (CFU) per milliliter $(\mathrm{ml})$ of urine were taken as significant. Low count significant bacteriuria $\left(10^{4}-10^{5} \mathrm{CFU} / \mathrm{ml}\right)$ was taken into consideration if there was any indication which can lower the concentration of bacteria in the urine.

Identification of significant isolates was done based on morphological appearance of the colonies, Gram's staining reactions and different biochemical reactions.

Antibiotic susceptibility testing: Antibiotics sensitivity testing of bacterial isolates was done by modified Kirby Bauer disc diffusion method as recommended by CLSI (2014) on MHA.

Statistical analysis: Data were entered into SPSS version 19.0 and analyzed for descriptive statistics.

\section{RESULTS}

Among total samples received in laboratory for culture, $269(89.7 \%)$ samples were mid- stream urine, 30(10\%) samples were catheter and remaining $1(0.3 \%)$ samples were suprapubic aspirate.

Out of 300 samples, 65(21.6\%) samples had significant growth. Among 65 samples, 55(84.6\%) were mid-stream urine samples (MSU) and 10(15.3\%) were catheter samples. Out of 201 samples from outdoor patients, $45(22.3 \%)$ samples and out of 99 samples from indoor patients, 20(20.2\%) samples had significant growth respectively. Among 138 samples from male patients, $26(18.8 \%)$ samples had significant growth. Similarly, $39(24.1 \%)$ out of 162 samples from female patients showed significant growth. Among the 65 significant growth cultures, high percentage $(35.8 \%)$ was obtained from age group 31-40 years.

\section{Bacterial isolates causing UTI}

Among the bacterial isolates, E. coli (49.2\%) was found to be the most predominant organism followed by Staphylococcus aureus (15.3\%), Klebsiella spp.(10.7\%) and others $(24.6 \%)$. 


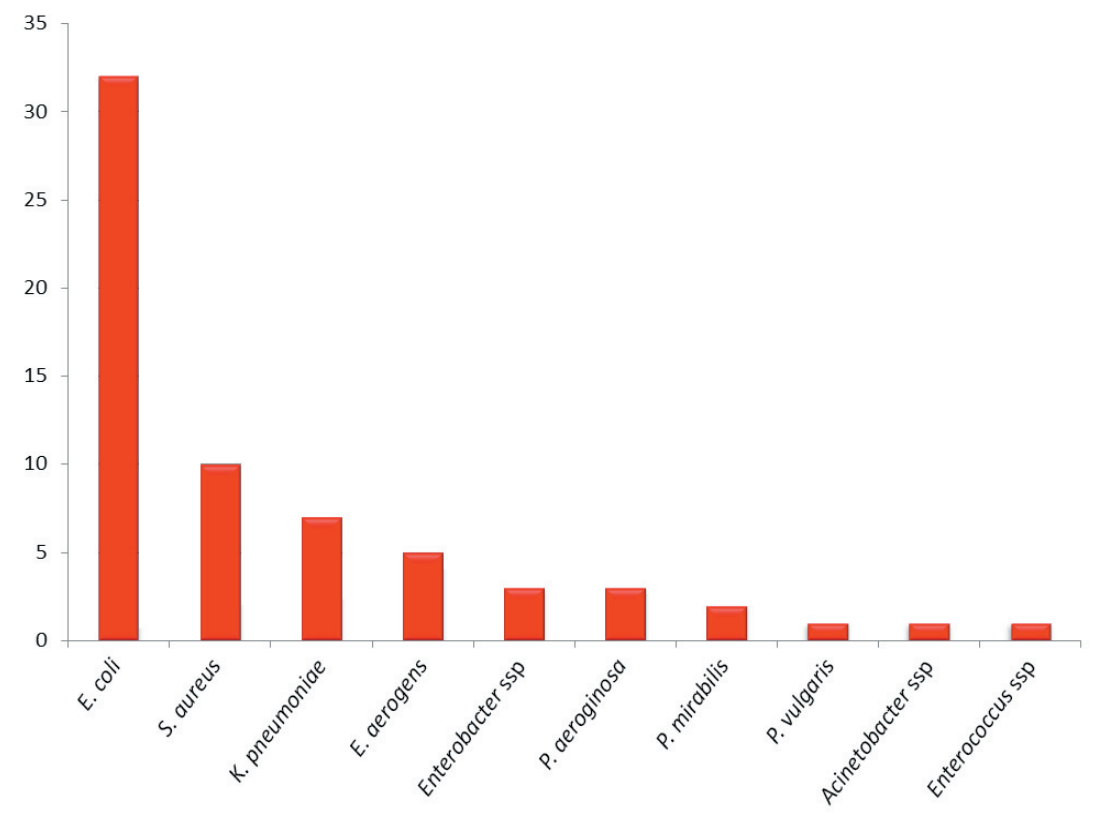

Figure 1: Pattern of bacterial isolates causing urinary tract infection

\section{Antibiotic susceptibility profile}

More proportion of $E$. coli was found to be sensitive towards Ceftriaxone (93.5\%) followed by Nitrofurantoin (87.5\%), Gentamicin (78.1\%), Ciprofloxacin and Norfloxacin $(71.8 \%)$, Imipenem and Chloramphenicol (65.6\%), Cotrimoxazole (59.3\%), and Cefixime (56.2\%). E. coli was found resistant towards Nalidixic acid (84.3\%) followed by Amoxycillin (75\%) and Amikacin (50\%).

S. aureus was found sensitive towards Amikacin (80\%) followed by Imipenem and Gentamicin (70\%) whereas it was found resistant to Amoxycillin (70\%). All Enterococcus isolates were found sensitive towards Cotrimoxazole and Nitrofurantoin.
Klebsiella spp was found sensitive towards Imipenem and Ceftriaxone (71.4\%) followed by Ciprofloxacin, Gentamicin $(57.1 \%)$ whereas it was found resistant towards Amoxycilin (85.7\%) followed by Norfloxacin (71.4\%), Cotrimoxazole (57.1\%) and Amikacin (57.1\%).

Pseudomonas aeruginosa was sensitive towards Gentamicin whereas it was resistant towards Levofloxacin (66.6\%) followed by Amoxycilin, Norfloxacin and Piperacilin (33.3\%).

Acinetobacter spp. were sensitive to Norfloxacin, Ciprofloxacin and Ceftriaxone whereas were resistant towards Cotrimoxazole, Nitrofurantoin, Amoxycilin and Nalidixic acid.

Table 1: Antibiotic resistance pattern of isolated bacteria in percentage

\begin{tabular}{|c|c|c|c|c|c|c|c|c|c|c|c|c|c|}
\hline Bacteria & 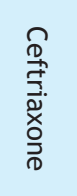 & 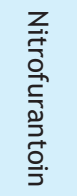 & 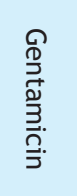 & 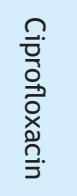 & 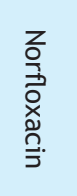 & 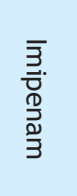 & $\begin{array}{l}\frac{\rho}{3} \\
\frac{0}{0} \\
\frac{0}{3} \\
\frac{0}{7} \\
\frac{0}{J} .\end{array}$ & 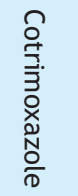 & $\begin{array}{l}\text { D } \\
\text { 爻. } \\
\text { 壱. }\end{array}$ & 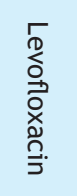 & 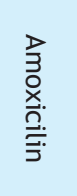 & 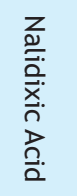 & 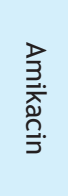 \\
\hline E. coli & 6.2 & 12.5 & 21.8 & 28.1 & 28.1 & 4.3 & 34.3 & 40.6 & 42.7 & 46.6 & 75 & 84.3 & 50 \\
\hline S. aureus & - & 40 & 30 & - & - & 30 & - & 50 & - & - & 70 & - & 20 \\
\hline Enterococcus spp & - & 0 & - & 100 & - & 100 & - & 0 & - & - & 100 & - & 100 \\
\hline Klebsiella spp & 28.5 & - & 42.8 & 42.8 & 71.4 & 28.5 & - & 57.1 & - & - & 85.7 & - & 57.1 \\
\hline P. aeruginosa & - & 33.3 & - & - & 33.3 & - & - & & - & 66.6 & 33.3 & - & - \\
\hline Acenetobacter spp & 0 & 100 & - & 0 & 0 & - & - & 100 & - & - & 100 & 100 & - \\
\hline Enterobacter spp & 0 & 37.5 & 37.5 & - & 37.5 & 12.5 & - & 12.5 & 75 & - & 50 & - & - \\
\hline Proteus spp & 33.3 & 33.3 & 33.3 & 66.6 & 0 & - & - & 66.6 & - & - & 33.3 & 33.3 & - \\
\hline
\end{tabular}




\section{DISCUSSION}

Age group 31-40 years had got the high prevalence of UTI which is in contradictory to the study by Daniyan and Ojha (2013). More than one third patients of the total UTI positive cases were found in this age group which is similar to the study of Leigh (1990). Leigh (1990) had found that nuns and unmarried women have lower prevalence of UTI in compared to married women. In addition, use of spermicidal coated condoms dramatically alters the normal bacterial flora and has been associated with marked increase in vaginal colonization with $E$. coli and in the risk of UTI (Braunwald et al. 2001).

The majority cases were from outpatient department and $33 \%$ were from patients admitted to the hospital. In comparison to males, higher number of urine samples was collected from females which is also similar to other studies (Arjunan et al. 2010; Alzohairy and Khadri 2011). The increased incidence of the urinary tract infection in women is conditioned by favoring anatomic factors, by hormonal changes and by the urodynamic disturbance occurring with age (Bobos et al. 2010).

In this study, $21.6 \%$ urine specimens from suspected UTI patients gave significant growth. Similar results were reported by other investigators from Nepal (Chhetri et al. 2001; Kumari et al. 2005) and rest of the world (Bashir et al. 2009). Among the bacterial isolates, E. coli was found to be the most predominant organism followed by S. aureus, Klebsiella spp. and other which is similar to the study of Kattel et al. (2008). However, Aboderin et al. (2009) reported Pseudomonas aeruginosa and Klebsiella spp respectively as the predominant bacteria.

Majority of E. coli were isolated from outpatient department. E.coli accounts for $50 \%-90 \%$ of all the uncomplicated urinary tract infections (Vgaarali et al. 2008). In our study, Staphylococcus aureus was found the second most common isolates. UTI due to Enterococcus faecalis are usually associated with the use of instrument or catheterization (Collier et al. 1998).

\section{CONCLUSION}

The main cause of the UTIs is Gram negative bacteria. Gentamicin and Ceftriaxone may be drug of choice for Gram negative bacteria whereas Amikacin and Ciprofloxacin may be drug of choice for Gram positive bacteria.

\section{ACKNOWLEDGEMENTS}

We would like to express heartfelt gratitude to all the patients participated in this study and the laboratory staff involved at Microbiology Laboratory at Ganeshman Singh Memorial Hospital and Research Center for providing the necessary materials and equipment for this study.

\section{CONFLICT OF INTEREST}

The authors declare no conflict of interest.

\section{REFERENCES}

Aboderin OA, Abdu A, Odetoyinbo BW and Lamikanra A (2009). Antimicrobial resistance in Escherichia coli strains from urinary tract infections. Natl Med Assoc 101: 1268-1273.

Abou-Dobara MI, Deyab MA, Elsawy EM and Mohamed HH (2012). Antibiotic susceptibility and genotype patterns of Escherichia coli, Klebsiella pneumoniae and Pseudomonas aeruginosa isolated from urinary tract infected patients. Pol J Microbiol 59(3): 207-212.

Alzohairy M and Khadri H (2011). Frequency and antibiotic susceptibility pattern of uro-pathogens isolated from community and hospital-acquired infections in Saudi Arabia- A prospective case study. Br J Med Med Res 1(2): 45-56.

Arjunan M, Al-Salamah AA and Amuthan M (2010). Prevalence and antibiotic susceptibility of uropathogens in patients from a rural environment, Tamilnadu. Am J Infect Dis 6(2): 29-33.

Bashir MF, Qazi JI, Ahmad N and Riaz S (2008). Diversity of urinary tract pathogens and drug resistant isolates of Escherichia coli in different age and gender groups of Pakistanis. Trop J Pharm Res 7(3): 1025-1031.

Benjamin WD, Biran KP and Gary VD (2009). Lactobacillus deldrueckii as the cause of urinary tract infection. J Clin Microbiol 47: 275-277.

Braunwald E, Fauci AS, Kasper DL, Hauser SL, Longo DL and Jameson JL (2001). Principles of Internal Medicine, McGraw-Hill, New York USA, 15 Ed. 2: 620-625.

Cheesbrough M (2000). District laboratory practice in tropical countries (Part 2) Cambridge University press. 
Chhetri PK, Rai SK and Pathak UN (2001). Retrospective study on urinary tract infection at Nepal Medical College Teaching Hospital, Kathmandu. Nepal Med Coll J 3: 83-85.

Collier L, Balows A and Sussman M (1998). Topley and Wilson's Microbiology and Microbial infections (9th ed) London: Oxford University Press 3: 601-621.

Daniyan SY and Ojha BA (2013). Prevalence and antimicrobial susceptibility of urine pathogen among patient in tertiary health institution in Ado Ekiti, Nigera. International Journal of Biomedical and Advance Research 4(2): 841.

Forbes BA, Sham DF and Weissfeld AS (2007). Infections of the urinary tract. In Bailey and Scott's Diagnostic Microbiology, 12th edition. St. Louis; Mosby Elsevier: 842- 55.

Haider G, Zehra N, Afroze A and Haider A (2010). Risk factors of urinary tract infection in pregnancy. $J$ Pak Med Assoc 60: 213-216.

Kattel HP, Acharya J, Mishar SK, Rijal BP and Pokhrel BM (2008). Bacteriology of urinary tract infection among patients attending Tribhuvan University teaching hospital, Kathmandu, Nepal. JNAMLS 9(1): 25-29.

Kumari N, Ghimire G, Magar JK, Mohapatra TM and Rai A (2005). Antibiogram pattern of isolates from UTI cases in Eastern part of Nepal. Nepal Med Coll J 7: 116-118.

Leigh DA (1990). UTI. In: Smith GR and Easmon CSF, In (eds) Toperly and Wilson,s Principles of Bacteriology, Virology and immunity, Bacterial Diseases, $8^{\text {th }}$ ed. Frome and London: Bulter and Tanner Ltd. 3: 197214.

Manikandan S, Ganesapandian S, Singh M and Kumaraguru AK (2011). Emerging of multidrug resistance human pathogens from urinary tract infections. Current Research in Bacteriology 4(1): 9-15.

Manjunath GN, Prakash R, Vamseedhar A and Shetty $\mathrm{K}$ (2011). Changing trends in the spectrum of antimicrobial drug resistance pattern of uropathogens isolated from hospital and community patients with urinary tract infections in Tumkur and Bangalore. Int J Biol Med Res 2(2): 504-507.

Mohammadi M (2007). Antimicrobial Resistance patterns of E. coli detected from hospitalized urine samples. Asian Journal of Biomedical Sciences 3(4): 195-201.

Pokhrel BM (2006). A handbook of clinical microbiology, 1st ed. Gorakhnath Desktop and Printing Supports, Kathmandu, Nepal.

Ramesh N, Sumathi CS, Balasubramanian V, Palaniappan KR and Kannan VR (2008). Urinary tract infection and antimicrobial susceptibility pattern of extended spectrum of beta lactamase producing clinical isolates. Advan Biol Res 2(5-6): 78-82.

Richards MJ, Edwards JR, Culver DH and Gaynes RP (1999). Nosocomial infections in medical intensive care units in the United States. Crit Care Med 27: 887

Taher M, Mohamed F, Ghaith M and Ismail M (2009) Prevalence and predictors of asymptomatic bacteriuria among pregnant women attending primary health care in Quatar. Middle East J Fam Med 7: 10-13.

Vgaarali MA, Karadesai SG, Patil CS, Metgud SC and Mutnal MB (2008). Haemagglutination and siderophore production as the urovirulence markers of the uropathogenic Escherichia coli. Indian J Med Micro-biol 26(1): 68-70 